\title{
Management of hyperglycaemia in type 2 diabetes: a consensus algorithm for the initiation and adjustment of therapy
}

\author{
A consensus statement from the American Diabetes Association and the European \\ Association for the Study of Diabetes
}

\author{
D. M. Nathan • J. B. Buse • M. B. Davidson • \\ R. J. Heine • R. R. Holman • R. Sherwin • B. Zinman \\ Published online: 27 June 2006 \\ (C) Springer-Verlag 2006
}

This document was reviewed and approved by the Professional
Practice Committee of the American Diabetes Association and by an
ad hoc committee of the European Association for the Study of
Diabetes (U. Smith, Gothenburg, Sweden; S. Del Prato, Pisa, Italy;
C. Bailey, Birmingham, UK; and B. Charbonnel, Nantes, France).
Simultaneous publication: This article is being simultaneously
published in 2006 in Diabetes Care and Diabetologia by the
American Diabetes Association and the European Association for the
Study of Diabetes. Copyright 2006 by the American Diabetes
Association, Inc. and Springer. Copying with attribution allowed for
any noncommercial use of the work.

D. M. Nathan $(\bowtie)$

Diabetes Center, Massachusetts General Hospital and Harvard

Medical School,

Boston, MA, USA

e-mail: dnathan@partners.org

J. B. Buse

University of North Carolina School of Medicine,

Chapel Hill, NC, USA

\section{B. Davidson}

Clinical Trials Unit, Charles R. Drew University,

Los Angeles, CA, USA

\section{R. J. Heine}

Diabetes Center, VU University Medical Center,

Amsterdam, The Netherlands

\section{R. R. Holman}

Diabetes Trials Unit, Oxford Centre for Diabetes, Endocrinology and Metabolism, Oxford University,

Oxford, UK

\section{R. Sherwin}

Department of Internal Medicine and Endocrinology,

Yale University School of Medicine,

New Haven, CT, USA

\section{B. Zinman}

Departments of Endocrinology and Metabolism,

Mount Sinai Hospital, University of Toronto,

Toronto, ON, Canada

\author{
Abbreviations \\ CVD cardiovascular disease \\ GLP-1 glucagon-like peptide 1 \\ SMBG self-monitoring of blood glucose \\ TZD thiazolidinedione \\ UKPDS UK Prospective Diabetes Study
}

\section{Introduction}

The epidemic of type 2 diabetes in the latter part of the 20 th and in the early 21 st century, and the recognition that achieving specific glycaemic goals can substantially reduce morbidity, have made the effective treatment of hyperglycaemia a top priority [1-3]. While the management of hyperglycaemia, the hallmark metabolic abnormality associated with type 2 diabetes, has historically had centre stage in the treatment of diabetes, therapies directed at other coincident features, such as dyslipidaemia, hypertension, hypercoagulability, obesity and insulin resistance, have also been a major focus of research and therapy. Maintaining glycaemic levels as close to the non-diabetic range as possible has been demonstrated to have a powerful beneficial impact on diabetes-specific complications, including retinopathy, nephropathy and neuropathy in the setting of type 1 diabetes $[4,5]$; in type 2 diabetes, more intensive treatment strategies have likewise been demonstrated to reduce complications [6-8]. Intensive glycaemic management resulting in lower $\mathrm{HbA}_{1 \mathrm{c}}$ levels has also been shown to have a beneficial effect on cardiovascular disease (CVD) complications in type 1 diabetes $[9,10]$; however, the role of intensive diabetes therapy on CVD in type 2 diabetes remains under active investigation $[11,12]$. Some therapies directed at lowering glucose levels have additional benefits with regard to CVD 
risk factors, while others lower glucose without additional benefits.

The development of new classes of blood glucoselowering medications to supplement the older therapies, such as lifestyle-directed interventions, insulin, sulfonylureas and metformin, has increased the treatment options for type 2 diabetes. Whether used alone or in combination with other blood glucose-lowering interventions, the availability of the newer agents has provided an increased number of choices for practitioners and patients and heightened uncertainty regarding the most appropriate means of treating this widespread disease. Although numerous reviews on the management of type 2 diabetes have been published in recent years [13-16], practitioners are often left without a clear pathway of therapy to follow. We developed the following consensus approach to the management of hyperglycaemia in the non-pregnant adult to help guide health care providers in choosing the most appropriate interventions for their patients with type 2 diabetes.

\section{Process}

The guidelines and algorithm that follow are based on clinical trials that have examined different modalities of therapy of type 2 diabetes and on the authors' clinical experience and judgment, keeping in mind the primary goal of achieving and maintaining glucose levels as close to the non-diabetic range as possible. The paucity of high-quality evidence in the form of clinical trials that directly compare different diabetes treatment regimens remains a major impediment to recommending one class of drugs, or a particular combination of therapies, over another. While the algorithm that we propose is likely to engender debate, we hope that the recommendations will help guide the therapy of type 2 diabetes and result in improved glycaemic control and health status over time.

\section{Glycaemic goals of therapy}

Controlled clinical trials, such as the DCCT [4] and the Stockholm Diabetes Intervention Study [5] in type 1 diabetes, and the UK Prospective Diabetes Study (UKPDS) $[6,7]$ and Kumamoto study [8] in type 2 diabetes, have helped to establish the glycaemic goals of therapy that result in improved long-term outcomes. Although the various clinical trials have had different designs, interventions and measured outcomes, the trials, in concert with epidemiological data $[17,18]$, support decreasing glycaemia as an effective means of reducing long-term microvascular and neuropathic complications. The most appropriate target levels for blood glucose, on a day-to-day basis, and $\mathrm{HbA}_{1 \mathrm{c}}$, as an index of chronic glycaemia, have not been systematically studied. However, both the DCCT [4] and the UKPDS $[6,7]$ had as their goals the achievement of glycaemic levels in the non-diabetic range. Neither study was able to sustain $\mathrm{HbA}_{1 \mathrm{c}}$ levels in the non-diabetic range in their intensive-treatment groups, achieving mean levels over time of $\sim 7 \%$, four standard deviations above the nondiabetic mean.

The most recent glycaemic goal recommended by the American Diabetes Association, selected on the basis of practicality and the projected reduction in complications over time, is 'in general' an $\mathrm{HbA}_{1 \mathrm{c}}$ level of $<7 \%$ [19]. For 'the individual patient', the $\mathrm{HbA}_{1 \mathrm{c}}$ should be 'as close to normal $(<6 \%)$ as possible without significant hypoglycemia'. The most recent glycaemic goal set by the European Union-International Diabetes Federation is an $\mathrm{HbA}_{1 \mathrm{c}}$ level $<6.5 \%$. The upper limit of the non-diabetic range is $6.1 \%$ (mean $\mathrm{HbA}_{1 \mathrm{c}}$ of $5 \%+2 \mathrm{SD}$ ) with the DCCT-standardised assay, which has been promulgated through the National Glycohemoglobin Standardization Program (NGSP) and adopted by the vast majority of commercially available assays [20]. Our consensus is that an $\mathrm{HbA}_{1 \mathrm{c}}$ of $\geq 7 \%$ should serve as a call to action to initiate or change therapy, with the goal of achieving an $\mathrm{HbA}_{1 \mathrm{c}}$ level as close to the non-diabetic range as possible or, at a minimum, decreasing the $\mathrm{HbA}_{1 \mathrm{c}}$ to $<7 \%$. We are mindful that this goal is not appropriate or practical for some patients, and clinical judgment, based on the potential benefits and risks of a more intensified regimen, needs to be applied for every patient. Factors such as life expectancy and risk of hypoglycaemia need to be considered for every patient before intensifying therapeutic regimens.

Assiduous attention to abnormalities other than hyperglycaemia that accompany type 2 diabetes, such as hypertension and dyslipidaemia, has been shown to improve microvascular and cardiovascular complications. Readers are referred to published guidelines for a discussion of the rationale and goals of therapy for the nonglycaemic risk factors, as well as recommendations on how to achieve them $[1,21,22]$.

\section{Principles in selecting antihyperglycaemic interventions}

Choosing specific antihyperglycaemic agents is predicated on their effectiveness in lowering glucose, extraglycaemic effects that may reduce long-term complications, safety profiles, tolerability and expense.

Effectiveness in lowering glycaemia Apart from their differential effects on glycaemia, there are insufficient data at this time to support a recommendation of one class of glucose-lowering agents, or one combination of medications, over others with regard to effects on complications. In other words, the salutary effects of therapy on long-term 
complications appear to be predicated predominantly on the level of glycaemic control achieved rather than on any other specific attributes of the intervention(s) used to achieve glycaemic goals. The UKPDS compared three classes of glucose-lowering medications (sulfonylurea, metformin or insulin) but was unable to demonstrate clear superiority of any one drug over the others with regard to complications $[6,7]$. However, the different classes do have variable effectiveness in decreasing glycaemic levels (Table 1), and the overarching principle in selecting a particular intervention will be its ability to achieve and maintain glycaemic goals. In addition to the intention-to-treat analyses demonstrating the superiority of intensive vs conventional interventions, the DCCT and UKPDS demonstrated a strong correlation between mean $\mathrm{HbA}_{1 \mathrm{c}}$ levels over time and the development and progression of retinopathy and nephropathy $[23,24]$. Therefore, we think it is reasonable to judge and compare blood glucose-lowering medications, and the combinations of such agents, primarily on the basis of the $\mathrm{HbA}_{1 \mathrm{c}}$ levels that are achieved and on their specific side effects, tolerability and expense.

Non-glycaemic effects of medications In addition to variable effects on glycaemia, specific effects of individual therapies on CVD risk factors, such as hypertension or dyslipidaemia, were also considered important. Additionally, we included the effects of interventions that may benefit or worsen the prospects for long-term glycaemic control in our recommendations. Examples of these would be changes in body mass, insulin resistance or insulin secretory capacity in type 2 diabetic patients.

\section{Choosing specific diabetes interventions and their roles in treating type 2 diabetes}

Numerous reviews have focused on the characteristics of the specific diabetes interventions listed below [25-33]. The aim here is to provide enough information to justify the choices of medications, the order in which they are recommended, and the utility of combinations of therapies. Unfortunately, there is a dearth of high-quality studies that provide head-tohead comparisons of the ability of the medications to achieve the currently recommended glycaemic levels. The authors highly recommend that such studies be conducted. However, even in the absence of rigorous, comprehensive studies that directly compare the efficacy of all available glucoselowering treatments and their combinations, we feel that there are enough data regarding the characteristics of the individual interventions to provide the guidelines below.

An important intervention that is likely to improve the probability that a patient will have better long-term control of diabetes is to make the diagnosis early, when the metabolic abnormalities of diabetes are usually less severe. Lower levels of glycaemia at time of initial therapy are associated with lower $\mathrm{HbA}_{1 \mathrm{c}}$ over time and decreased longterm complications [34].

Lifestyle interventions The major environmental factors that increase the risk of type 2 diabetes, presumably in the setting of genetic risk, are overnutrition and a sedentary lifestyle, with consequent overweight and obesity [35]. Not surprisingly, interventions that reverse or improve these factors have been demonstrated to have a beneficial effect on control of glycaemia in established type 2 diabetes [36]. While there is still active debate regarding the most beneficial types of diet and exercise, weight loss almost always improves glycaemic levels. Unfortunately, the high rate of weight regain has limited the role of lifestyle interventions as an effective means of controlling glycaemia in the long term. The most convincing long-term data that weight loss effectively lowers glycaemia have been generated in the follow-up of type 2 diabetic patients who have had bariatric surgery $[37,38]$. In this setting, diabetes is virtually erased, with a mean sustained weight loss of $>20 \mathrm{~kg}[37,38]$. Studies of the pharmacological treatment of obesity have been characterised by high drop-out rates, low sustainability, and side effects; weight loss medications cannot be recommended as a primary therapy for diabetes at this time. In addition to the beneficial effects of weight loss on glycaemia, weight loss and exercise improve coincident CVD risk factors, such as blood pressure and atherogenic lipid profiles, and ameliorate other consequences of obesity [37-40]. There are few adverse consequences of such lifestyle interventions other than the difficulty in incorporating them into usual lifestyle and sustaining them, and the usually minor musculoskeletal injuries and potential problems associated with neuropathy, such as foot trauma and ulcers, that may occur with increased activity. Theoretically, effective weight loss, with its pleiotropic benefits, safety profile and low cost, should be the most cost-effective means of controlling diabetes, if it could be achieved and maintained long term.

Given these beneficial effects, a lifestyle intervention programme to promote weight loss and increase activity levels should, with rare exceptions, be included as part of diabetes management. The beneficial effects of such programmes are usually seen rapidly, within weeks to months, and often before there has been substantial weight loss [41]. Weight loss of as little as $4 \mathrm{~kg}$ will often ameliorate hyperglycaemia. However, the limited long-term success of lifestyle programmes to maintain glycaemic goals in patients with type 2 diabetes suggests that a large majority of patients will require the addition of medications over the course of their diabetes. 
Table 1 Summary of antidiabetic interventions as monotherapy

\begin{tabular}{|c|c|c|c|}
\hline Interventions & $\begin{array}{l}\text { Expected } \\
\text { decrease in } \\
\mathrm{HbA}_{1 \mathrm{c}}(\%)\end{array}$ & Advantages & Disadvantages \\
\hline \multicolumn{4}{|l|}{ Step 1: initial } \\
\hline $\begin{array}{l}\text { Lifestyle to decrease weight and } \\
\text { increase activity }\end{array}$ & $1-2$ & Low cost, many benefits & Fails for most in first year \\
\hline Metformin & 1.5 & Weight neutral, inexpensive & GI side effects, rare lactic acidosis \\
\hline \multicolumn{4}{|l|}{ Step 2: additional therapy } \\
\hline Insulin & $1.5-2.5$ & $\begin{array}{l}\text { No dose limit, inexpensive, } \\
\text { improved lipid profile }\end{array}$ & $\begin{array}{l}\text { Injections, monitoring, hypoglycaemia, } \\
\text { weight gain }\end{array}$ \\
\hline Sulfonylureas & 1.5 & Inexpensive & Weight gain, hypoglycaemia ${ }^{\mathrm{a}}$ \\
\hline TZDs & $0.5-1.4$ & Improved lipid profile & Fluid retention, weight gain, expensive \\
\hline \multicolumn{4}{|l|}{ Other drugs } \\
\hline$\alpha$-Glucosidase inhibitors & $0.5-0.8$ & Weight neutral & $\begin{array}{l}\text { Frequent GI side effects, three times/day } \\
\text { dosing, expensive }\end{array}$ \\
\hline Exenatide & $0.5-1.0$ & Weight loss & $\begin{array}{l}\text { Injections, frequent GI side effects, } \\
\text { expensive, little experience }\end{array}$ \\
\hline Glinides & $1-1.5^{\mathrm{b}}$ & Short duration & Three times/day dosing, expensive \\
\hline Pramlintide & $0.5-1.0$ & Weight loss & $\begin{array}{l}\text { Injections, three times/day dosing, frequent } \\
\text { GI side effects, expensive, little experience }\end{array}$ \\
\hline
\end{tabular}

${ }^{a}$ Severe hypoglycaemia is relatively infrequent with sulfonylurea therapy. The longer-acting agents (e.g. chlorpropamide, glyburide [glibenclamide], and sustained-release glipizide) are more likely to cause hypoglycaemia than glipizide, glimepiride and gliclazide. ${ }^{\mathrm{b}}$ Repaglinide is more effective at lowering $\mathrm{HbA}_{1 \mathrm{c}}$ than nateglinide. GI Gastrointestinal

Medications The characteristics of currently available antidiabetic interventions, when used as monotherapy, are summarised in Table 1. The glucose-lowering effectiveness of individual therapies and combinations demonstrated in clinical trials is predicated not only on the intrinsic characteristics of the intervention, but also on the baseline glycaemia, duration of diabetes, previous therapy and other factors. A major factor in selecting a class of drugs, or a specific medication within a class, to initiate therapy or when changing therapy, is the ambient level of glycaemic control. When levels of glycaemia are high (e.g. $\mathrm{HbA}_{1 \mathrm{c}}>$ $8.5 \%$ ), classes with greater and more rapid glucoselowering effectiveness, or potentially earlier initiation of combination therapy, are recommended; conversely, when glycaemic levels are closer to the target levels (e.g. $\mathrm{HbA}_{1 \mathrm{c}}<7.5 \%$ ), medications with lesser potential to lower glycaemia and/or a slower onset of action may be considered. Obviously, the choice of glycaemic goals and the medications used to achieve them must be individualised for each patient, balancing the potential for lowering $\mathrm{HbA}_{1 \mathrm{c}}$ and anticipated long-term benefit with specific safety issues, as well as other characteristics of regimens, including side effects, tolerability, patient burden and longterm adherence, expense and the non-glycaemic effects of the medications. Finally, type 2 diabetes is a progressive disease, with worsening glycaemia over time. Therefore, addition of medications is the rule, not the exception, if treatment goals are to continue to be met.
Metformin Metformin is the only biguanide available in most of the world. Its major effect is to decrease hepatic glucose output and lower fasting glycaemia. Typically, metformin monotherapy will lower $\mathrm{HbA}_{1 \mathrm{c}}$ by $\sim 1.5$ percentage points $[27,42]$. It is generally well tolerated, with the most common adverse effects being gastrointestinal. Although always a matter of concern because of its potentially fatal outcome, lactic acidosis is quite rare $(<$ one case per 100,000 treated patients) [43]. Metformin monotherapy is usually not accompanied by hypoglycaemia and has been used safely, without causing hypoglycaemia, in patients with pre-diabetic hyperglycaemia [44]. The major nonglycaemic effect of metformin is either weight stability or modest weight loss, in contrast to many of the other blood glucose-lowering medications. The UKPDS demonstrated a beneficial effect of metformin therapy on CVD outcomes [7], which needs to be confirmed.

Sulfonylureas Sulfonylureas lower glycaemia by enhancing insulin secretion. They appear to have an effect similar to metformin, and they lower $\mathrm{HbA}_{1 \mathrm{c}}$ by $\sim 1.5$ percentage points [26]. The major adverse side effect is hypoglycaemia, but severe episodes, characterised by need for assistance, coma or seizure, are infrequent. However, such episodes are more frequent in the elderly. Episodes can be both prolonged and life threatening, although these are very rare. Several of the newer sulfonylureas have a relatively lower risk for hypoglycaemia (Table 1) $[45,46]$. In 
addition, weight gain of $\sim 2 \mathrm{~kg}$ is common with the initiation of sulfonylurea therapy. This may have an adverse impact on CVD risk, although this has not been established. Finally, sulfonylurea therapy was implicated as a potential cause of increased CVD mortality in the University Group Diabetes Program [47]. Concerns raised by the University Group Diabetes Program study that sulfonylurea therapy may increase CVD mortality in type 2 diabetes were not substantiated by the UKPDS [6].

Glinides Like the sulfonylureas, the glinides stimulate insulin secretion, although they bind to a different site within the sulfonylurea receptor [28]. They have a shorter circulating half-life than the sulfonylureas and must be administered more frequently. Of the two glinides currently available in the US, repaglinide is almost as effective as metformin or the sulfonylureas, decreasing $\mathrm{HbA}_{1 \mathrm{c}}$ by $\sim 1.5$ percentage points. Nateglinide is somewhat less effective in lowering $\mathrm{HbA}_{1 \mathrm{c}}$ than repaglinide when used as monotherapy or in combination therapy [48, 49]. The glinides have a similar risk for weight gain as the sulfonylureas, but hypoglycaemia may be less frequent, at least with nateglinide, than with some sulfonylureas [49, 50].

$\alpha$-Glucosidase inhibitors $\alpha$-Glucosidase inhibitors reduce the rate of digestion of polysaccharides in the proximal small intestine, primarily lowering postprandial glucose levels without causing hypoglycaemia. They are less effective in lowering glycaemia than metformin or the sulfonylureas, reducing $\mathrm{HbA}_{1 \mathrm{c}}$ by $0.5-0.8$ percentage points [29]. Since carbohydrate is absorbed more distally, malabsorption and weight loss do not occur; however, increased delivery of carbohydrate to the colon commonly results in increased gas production and gastrointestinal symptoms. This side effect has led to discontinuation of the $\alpha$-glucosidase inhibitors by $25-45 \%$ of participants in clinical trials [29, 51]. One clinical trial examining acarbose as a means of preventing the development of diabetes in high-risk subjects with impaired glucose tolerance showed an unexpected reduction in severe CVD outcomes [51]. This potential benefit of $\alpha$-glucosidase inhibitors needs to be confirmed.

Thiazolidinediones Thiazolidinediones (TZDs or glitazones) are peroxisome proliferator-activated receptor $\gamma$ modulators; they increase the sensitivity of muscle, fat and liver to endogenous and exogenous insulin ('insulin sensitisers') [31]. The limited data regarding the blood glucose-lowering effectiveness of TZDs when used as monotherapy have demonstrated a $0.5-1.4 \%$ decrease in $\mathrm{HbA}_{1 \mathrm{c}}$. The most common adverse effects with TZDs are weight gain and fluid retention. There is an increase in adiposity, largely subcutaneous, with redistribution of fat from visceral deposits shown in some studies. The fluid retention usually manifests as peripheral oedema, though new or worsened heart failure can occur. The TZDs either have a beneficial or neutral effect on atherogenic lipid profiles, with pioglitazone having a more beneficial effect than rosiglitazone $[52,53]$. The Prospective Pioglitazone Clinical Trial in Macrovascular Events (PROactive) study demonstrated no significant effects of pioglitazone compared with placebo on the primary CVD outcome (composite of all-cause mortality, non-fatal and silent myocardial infarction, stroke, major leg amputation, acute coronary syndrome, coronary artery bypass graft or percutaneous coronary intervention, and leg revascularisation) after 3 years of follow-up, but a $16 \%$ reduction in death, myocardial infarction, and stroke, a secondary endpoint, was reported with marginal statistical significance [54].

Insulin Insulin is the oldest of the currently available medications and has the most clinical experience. Although initially developed to treat the insulin-deficient type 1 diabetic patient, in whom it is life saving, insulin was used early on to treat the insulin-resistant form of diabetes recognised by Himsworth and Kerr [55]. Insulin is the most effective of diabetes medications in lowering glycaemia. It can, when used in adequate doses, decrease any level of elevated $\mathrm{HbA}_{1 \mathrm{c}}$ to, or close to, the therapeutic goal. Unlike the other blood glucose-lowering medications, there is no maximum dose of insulin beyond which a therapeutic effect will not occur. Relatively large doses of insulin $(\geq 1 \mathrm{U} / \mathrm{kg})$, compared with those required to treat type 1 diabetes, may be necessary to overcome the insulin resistance of type 2 diabetes and lower $\mathrm{HbA}_{1 \mathrm{c}}$ to the target value. Although initial therapy is aimed at increasing basal insulin supply, usually with intermediate- or long-acting insulins, patients may also require prandial therapy with short- or rapidacting insulins (Fig. 1). Insulin therapy has beneficial effects on triglyceride and HDL cholesterol levels [56], but is associated with weight gain of $\sim 2-4 \mathrm{~kg}$, probably proportional to the correction of glycaemia, and owing predominantly to the reduction of glycosuria. As with sulfonylurea therapy, the weight gain may have an adverse effect on cardiovascular risk. Insulin therapy is also associated with hypoglycaemia, albeit much less frequently than in type 1 diabetes. In clinical trials aimed at normoglycaemia and achieving a mean $\mathrm{HbA}_{1 \mathrm{c}}$ of $\sim 7 \%$, severe hypoglycaemic episodes (defined as requiring help from another person to treat) occurred at a rate of between 1 and 3 per 100 patient-years [8, 56-59] compared with 61 per 100 patient-years in the DCCT intensive-therapy group [4]. Insulin analogues with longer, non-peaking profiles may decrease the risk of hypoglycaemia compared with NPH, and analogues with very short durations of action may reduce the risk of hypoglycaemia compared with 
Fig. 1 Initiation and adjustment of insulin regimens. Insulin regimens should be designed taking lifestyle and meal schedule into account. The algorithm can only provide basic guidelines for initiation and adjustment of insulin. See [71] for more detailed instructions.

${ }^{a}$ Premixed insulins are not recommended during adjustment of doses; however, they can be used conveniently, usually before breakfast and/or dinner if the proportion of rapid- and intermediate-acting insulins is similar to the fixed proportions available. $b g$ Blood glucose

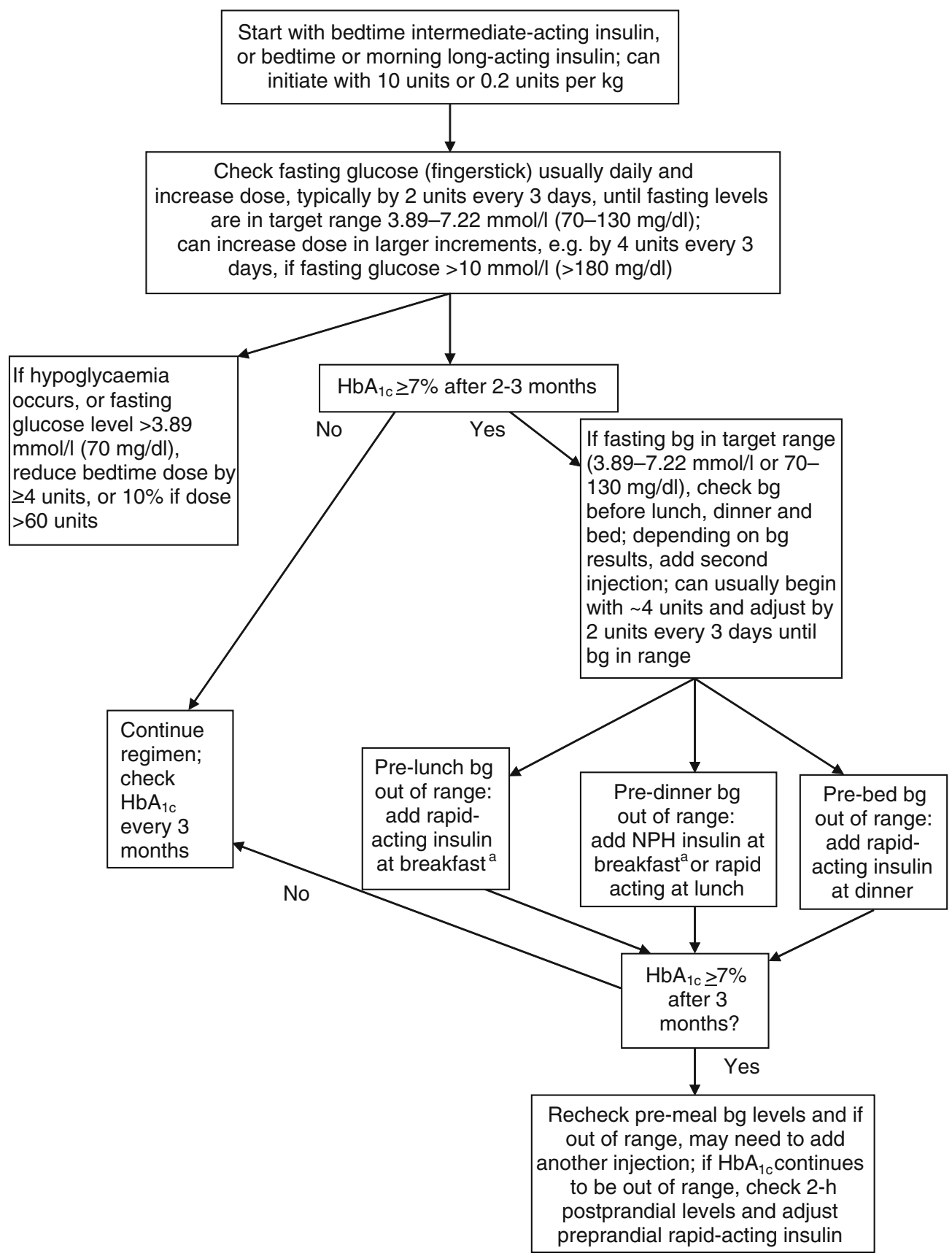

regular insulin $[60,61]$. Inhaled insulin was approved in the US in 2006 for the treatment of type 2 diabetes. Published clinical studies to date have not demonstrated whether inhaled insulin, given as monotherapy [62, 63] or in combination with an injection of long-acting insulin [64], can lower $\mathrm{HbA}_{1 \mathrm{c}}$ to $\leq 7 \%$.

Glucagon-like peptide 1 agonists (exenatide) Glucagonlike peptide 1 (GLP-1) 7-37, a naturally occurring peptide produced by the $\mathrm{L}$ cells of the small intestine, stimulates insulin secretion. Exendin-4 has homology with the human GLP-1 sequence but has a longer circulating half-life. It binds avidly to the GLP-1 receptor on the pancreatic beta cell and potentiates glucose-mediated insulin secretion [32]. Synthetic exendin-4 (exenatide) was approved for use in the US in 2005 and is administered twice per day by subcutaneous injection. Although there are far less published data on this new compound than the other blood glucose-lowering medications, exendin-4 appears to lower $\mathrm{HbA}_{1 \mathrm{c}}$ by $0.5-1$ percentage points, mainly by lowering 
postprandial blood glucose levels [65-68]. Exenatide also suppresses glucagon secretion and slows gastric motility. It is not associated with hypoglycaemia, but has a relatively high frequency of gastrointestinal side effects, with 30 $45 \%$ of treated patients experiencing one or more episodes of nausea, vomiting or diarrhoea [65-68]. In published trials, exenatide is associated with a weight loss of $\sim 2-3 \mathrm{~kg}$ over 6 months, some of which may be a result of its gastrointestinal side effects. Currently, exenatide is approved for use in the US with sulfonylurea and/or metformin.

Amylin agonists (pramlintide) Pramlintide is a synthetic analogue of the beta cell hormone amylin. Currently, pramlintide is approved for use in the US only as adjunctive therapy with insulin.

Pramlintide is administered subcutaneously before meals and slows gastric emptying, inhibits glucagon production in a glucose-dependent fashion, and predominantly decreases postprandial glucose excursions [33]. In clinical studies, $\mathrm{HbA}_{1 \mathrm{c}}$ has been decreased by $0.5-0.7$ percentage points [69]. The major clinical side effects of this drug, which is injected before meals, are gastrointestinal in nature. Approximately $30 \%$ of treated participants in the clinical trials have developed nausea. Weight loss associated with this medication is $\sim 1-1.5 \mathrm{~kg}$ over 6 months; as with exenatide, some of the weight loss may be the result of gastrointestinal side effects.

\section{How to initiate diabetes therapy and advance interventions}

Except in rare circumstances, such as patients who are extremely catabolic or hyperosmolar, unable to hydrate themselves adequately, or with diabetic ketoacidosis (see Special considerations/patients below), hospitalisation is not required to initiate or adjust therapy. The patient is the key player in the diabetes care team and should be trained and empowered to prevent and treat hypoglycaemia, as well as to adjust medications with the guidance of health care providers to achieve glycaemic goals. Many patients may be managed effectively with monotherapy; however, the progressive nature of the disease will require the use of combination therapy in many, if not most, patients over time to achieve and maintain glycaemia in the target range.

The measures of glycaemia that are initially targeted on a day-to-day basis are the fasting and preprandial glucose levels. Self-monitoring of blood glucose (SMBG) is an important element in adjusting or adding new interventions and, in particular, in titrating insulin doses. The need for and number of required SMBG measurements are not clear
[70] but are dependent on the medications used. Oral hypoglycaemic regimens that do not include sulfonylureas, and are therefore not likely to cause hypoglycaemia, usually do not require SMBG. However, SMBG may be used to determine whether therapeutic blood glucose targets are being achieved and to adjust treatment regimens without requiring the patient to have laboratory-based blood glucose testing. A fasting glucose level measured several times per week generally correlates well with the $\mathrm{HbA}_{1 \mathrm{c}}$ level. Insulin therapy requires more frequent monitoring.

The levels of plasma or capillary glucose (most meters that measure fingerstick capillary samples are adjusted to provide values equivalent to plasma glucose) that should result in long-term glycaemia in the non-diabetic target range, as measured by $\mathrm{HbA}_{1 \mathrm{c}}$, are fasting and preprandial levels between 3.89 and $7.22 \mathrm{mmol} / \mathrm{l}(70$ and $130 \mathrm{mg} / \mathrm{dl})$. If these levels are not consistently achieved, or $\mathrm{HbA}_{1 \mathrm{c}}$ remains above the desired target, postprandial levels, usually measured 90-120 min after a meal, may be checked. They should be less than $10 \mathrm{mmol} / \mathrm{l}(180 \mathrm{mg} / \mathrm{dl})$ to achieve $\mathrm{HbA}_{1 \mathrm{c}}$ levels in the target range.

Attempts to achieve target glycaemic levels with regimens including sulfonylureas or insulin may be associated with modest hypoglycaemia, with glucose levels in the 3.06-3.89-mmol $(55-70-\mathrm{mg} / \mathrm{dl})$ range. These episodes are generally well tolerated, easily treated with oral carbohydrate, such as glucose tablets or 120-180 ml juice or non-diet soda, and rarely progress to more severe hypoglycaemia including loss of consciousness or seizures.

\section{Algorithm}

The algorithm (Fig. 2) takes into account the characteristics of the individual interventions, their synergies, and expense. The goal is to achieve and maintain glycaemic levels as close to the non-diabetic range as possible and to change interventions at as rapid a pace as titration of medications allows. Pramlintide, exenatide, $\alpha$-glucosidase inhibitors and the glinides are not included in this algorithm, owing to their generally lower overall glucose-lowering effectiveness, limited clinical data and/or relative expense (Table 1). However, they may be appropriate choices in selected patients.

Step 1: lifestyle intervention and metformin. Based on the numerous demonstrated short- and long-term benefits that accrue when weight loss and increased levels of activity are achieved and maintained, and the cost-effectiveness of lifestyle interventions when they succeed, the consensus is that lifestyle interventions should be initiated as the first step in treating new-onset type 2 diabetes (Fig. 2). These interventions should be implemented by 
Fig. 2 Algorithm for the metabolic management of type 2 diabetes. Reinforce lifestyle intervention at every visit. a Check $\mathrm{HbA}_{1 \mathrm{c}}$ every 3 months until $\mathrm{HbA}_{1 \mathrm{c}}$ is $<7 \%$, and then at least every 6 months. b Although three oral agents can be used, initiation and intensification of insulin therapy is preferred based on effectiveness and expense. c See Fig. 1 for initiation and adjustment of insulin

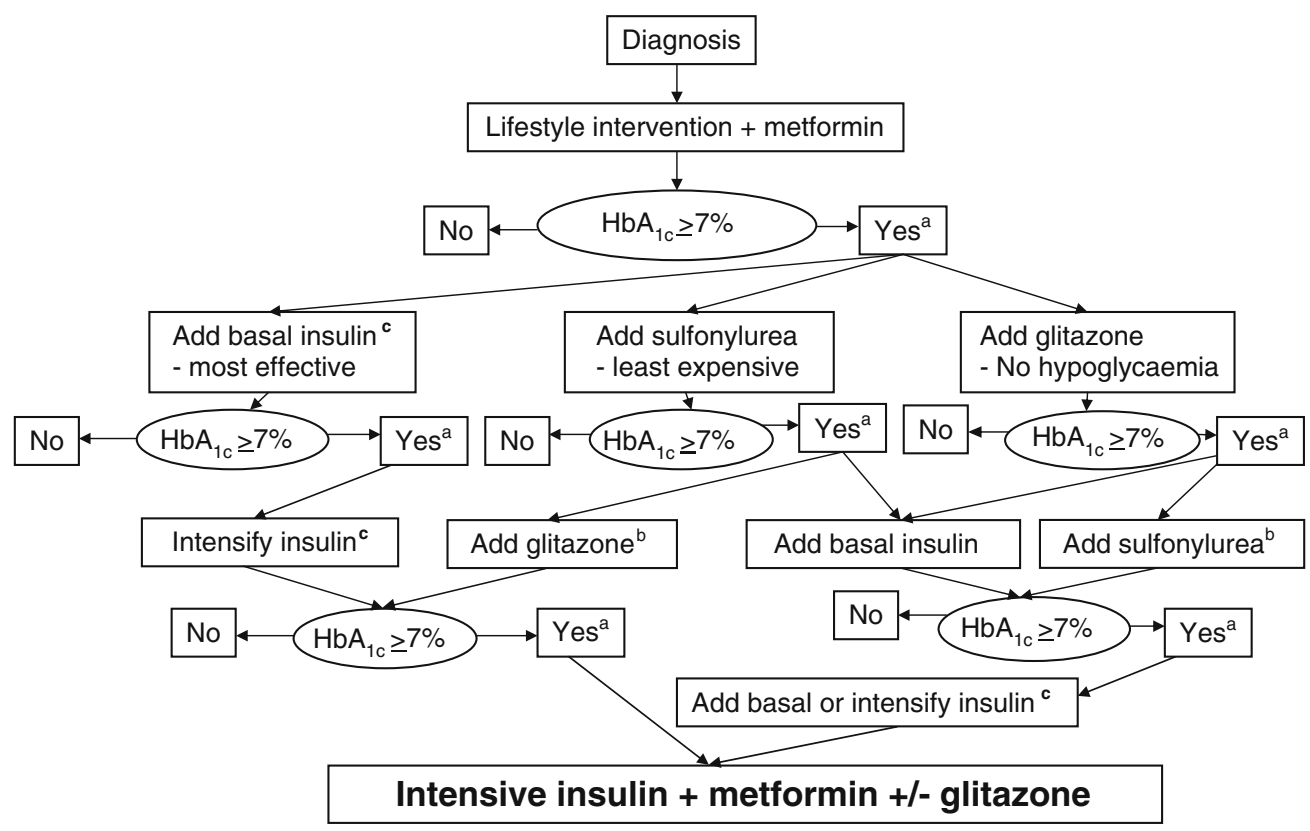

health care professionals with appropriate training, usually registered dietitians with training in behavioural modification, and be sensitive to ethnic and cultural differences among populations. Moreover, lifestyle interventions to improve glucose, blood pressure and lipids levels, and to promote weight loss or at least avoid weight gain, should remain an underlying theme throughout the management of type 2 diabetes, even after medications are used. For the $10-20 \%$ of patients with type 2 diabetes who are not obese or overweight, modification of dietary composition and activity levels may play a supporting role, but medications are generally required earlier (see Special considerations/ patients below).

The authors recognise that for most individuals with type 2 diabetes, lifestyle interventions fail to achieve or maintain metabolic goals, either because of failure to lose weight, weight regain, progressive disease or a combination of factors. Therefore, our consensus is that metformin therapy should be initiated concurrent with lifestyle intervention at diagnosis. Metformin is recommended as the initial pharmacological therapy, in the absence of specific contraindications, for its effect on glycaemia, absence of weight gain and hypoglycaemia, generally low level of side effects, high level of acceptance and relatively low cost. Metformin treatment should be titrated to its maximally effective dose over 1-2 months, as tolerated (Table 2). Rapid addition of other glucose-lowering medications should be considered in the setting of persistent symptomatic hyperglycaemia.

Step 2: additional medications. If lifestyle intervention and maximal tolerated dose of metformin fail to achieve or sustain glycaemic goals, another medication should be added within 2-3 months of the initiation of therapy or at any time when the $\mathrm{HbA}_{1 \mathrm{c}}$ goal is not achieved. There was no strong consensus regarding the second medication added after metformin other than to choose among insulin, a sulfonylurea or a TZD (Fig. 2). As discussed above, the $\mathrm{HbA}_{1 \mathrm{c}}$ level will determine in part which agent is selected next, with consideration given to the more effective glycaemia-lowering agent, insulin, for patients with a $\mathrm{HbA}_{1 \mathrm{c}}$ of $>8.5 \%$ or with symptoms secondary to hyperglycaemia. Insulin can be initiated with a basal (intermediate- or long-acting) insulin (see Fig. 1 for suggested initial

Table 2 Titration of metformin

1. Begin with low-dose metformin $(500 \mathrm{mg}$ ) taken once or twice per day with meals (breakfast and/or dinner).

2. After 5-7 days, if GI side effects have not occurred, advance dose to 850 or 1,000 mg before breakfast and dinner.

3. If GI side effects appear as doses advanced, can decrease to previous lower dose and try to advance dose at a later time.

4. The maximum effective dose is usually $850 \mathrm{mg}$ twice per day, with modestly greater effectiveness with doses up to $3 \mathrm{~g}$ per day. GI side effects may limit the dose that can be used.

5. Based on cost considerations, generic metformin is the first choice of therapy. A longer-acting formulation is available in some countries and can be given once per day.

GI Gastrointestinal 
insulin regimens) [71]. The relative increased cost of the newer agents that are only available as brand medications must be balanced against their relative benefits.

Step 3: further adjustments. If lifestyle, metformin and a second medication do not result in goal glycaemia, the next step should be to start, or intensify, insulin therapy (Fig. 1). When $\mathrm{HbA}_{1 \mathrm{c}}$ is close to goal $(<8.0 \%)$, addition of a third oral agent could be considered; however, this approach is relatively more costly and potentially not as effective in lowering glycaemia compared with adding or intensifying insulin [72]. Intensification of insulin therapy usually consists of additional injections that might include a shortor rapid-acting insulin given before selected meals to reduce postprandial glucose excursions (Fig. 1). When prandial rapid- or very rapid acting insulin injections are started, insulin secretagogues (sulfonylurea or glinides) should be discontinued, or tapered and then discontinued, since they are not considered synergistic with administered insulin.

\section{Rationale for selecting specific combinations}

More than one medication will be necessary for the majority of patients over time. Selection of the individual agents should be made on the basis of their glucoselowering effectiveness and other characteristics listed in Table 1. However, when adding second and, potentially, third antihyperglycaemic medications, the synergy of particular combinations and other interactions should be considered. In general, antihyperglycaemic drugs with different mechanisms of action will have the greatest synergy. Insulin plus metformin [73] and insulin plus a TZD [74] are particularly effective means of lowering glycaemia. The increased risk of fluid retention with the latter combination must be considered. (TZD in combination with insulin is not currently approved in the European Union.) Although both TZDs and metformin effectively increase sensitivity to insulin, they have different target organs and have been shown to have modest additive effects, with addition of TZD to metformin lowering $\mathrm{HbA}_{1 \mathrm{c}}$ by $0.3-0.8 \%[75,76]$.

\section{Special considerations/patients}

In the setting of severely uncontrolled diabetes with catabolism, defined as fasting plasma glucose levels $>13.9 \mathrm{mmol} / 1(250 \mathrm{mg} / \mathrm{dl})$, random glucose levels consistently $>16.7 \mathrm{mmol} / 1(300 \mathrm{mg} / \mathrm{dl}), \mathrm{HbA}_{1 \mathrm{c}}>10 \%$, or the presence of ketonuria, or as symptomatic diabetes with polyuria, polydipsia and weight loss, insulin therapy in combination with lifestyle intervention is the treatment of choice. Some patients with these characteristics will have unrecognised type 1 diabetes; others will have type 2 diabetes but with severe insulin deficiency. Insulin can be titrated rapidly and is associated with the greatest likelihood of returning glucose levels rapidly to target levels. After symptoms are relieved, oral agents can often be added and it may be possible to withdraw insulin, if preferred.

\section{Conclusions}

Type 2 diabetes is epidemic. Its long-term consequences translate into enormous human suffering and economic costs. We now understand that much of the morbidity

Summary
The guidelines and treatment algorithm presented here emphasise
the following
- Achievement and maintenance of normal glycaemic goals
- Initial therapy with lifestyle intervention and metformin
- Rapid addition of medications, and transition to new regimens,
when target glycaemic goals are not achieved or sustained
- Early addition of insulin therapy in patients who do not meet
target goals

associated with long-term complications can be substantially reduced with interventions that achieve glucose levels close to the non-diabetic range. Although new classes of medications, and numerous combinations, have been demonstrated to lower glycaemia, current-day management has failed to achieve and maintain the glycaemic levels most likely to provide optimal health care status for people with diabetes.

Duality of interest D. M. Nathan has received research grants for investigator-initiated research from Aventis and Novo Nordisk. J. B. Buse has conducted research and/or served on advisory boards under contract between the University of North Carolina and Amylin, Becton Dickinson, Bristol-Myers Squibb, Hoffman-LaRoche, Lilly, Novo Nordisk, Merck, Novartis, Pfizer and Sanofi-Aventis. M. B. Davidson has received research support from Eli Lilly, Merck, and Pfizer; has served on advisory boards for Amylin, GlaxoSmithKline, Merck and Sanofi-Aventis, and has been on speakers bureaus for Amylin, Eli Lilly, GlaxoSmithKline and Pfizer. R. J. Heine has received research support from GlaxoSmithKline, Minimed-Medtronic, Novartis and Novo Nordisk, and has served on advisory boards for Amylin, Bristol-Myers Squibb, Merck, Novartis, Novo Nordisk, Pfizer and Sanofi-Aventis. R. R. Holman has received research support from Bristol-Myers Squibb, GlaxoSmithKline, Merck Santé, Novo Nordisk, Pfizer and Pronova, and has served on advisory boards and/or received honoraria for speaking engagements from Amylin, GlaxoSmithKline, Lilly, Merck Sharp \& Dome, Novartis and Sanofi-Aventis. R. Sherwin has served on advisory boards for Amylin, Bristol-Myers Squibb, Eli Lilly, Merck and Takeda. B. Zinman has received research support from Eli Lilly, GlaxoSmithKline, Novartis and Novo Nordisk, and has been a member of scientific advisory boards and/or received honoraria for speaking engagements from Amylin, Eli Lilly, GlaxoSmithKline, Johnson \& Johnson, Merck, Novartis, Pfizer, Sanofi-Aventis and Smiths Medical. 


\section{References}

1. American Diabetes Association (2005) Standards of medical care of diabetes. Diabetes Care 28(Suppl 1):S15-S35

2. European Diabetes Policy Group (1999) A desk-top guide to type 2 diabetes mellitus. Diabet Med 16:716-730

3. The Royal College of General Practitioners Effective Clinical Practice Unit (2002) Clinical guidelines for type 2 diabetes mellitus: management of blood glucose (Article online). Available from http://www.nice.org.uk/pdf/NICE full blood glucose.pdf, last accessed in May 2006

4. Diabetes Control and Complications Trial Research Group (1993) The effect of intensive diabetes treatment on the development and progression of long-term complications in insulin-dependent diabetes mellitus: the Diabetes Control and Complications Trial. N Engl J Med 329:978-986

5. Reichard P, Nilsson B-Y, Rosenqvist U (1993) The effect of long-term intensified insulin treatment on the development of microvascular complications of diabetes mellitus. N Engl J Med 329:304-309

6. UK Prospective Diabetes Study (UKPDS) Group (1998) Intensive blood glucose control with sulphonylureas or insulin compared with conventional treatment and risk of complication in patients with type 2 diabetes (UKPDS 33). Lancet 352:837-853

7. UK Prospective Diabetes Study (UKPDS) Group (1998) Effect of intensive blood glucose control with metformin on complication in overweight patients with type 2 diabetes (UKPDS 34). Lancet 352:854-865

8. Ohkubo Y, Kishikawa H, Araki E et al (1995) Intensive insulin therapy prevents the progression of diabetic microvascular complications in Japanese patients with NIDDM: a randomized prospective 6-year study. Diabetes Res Clin Pract 28:103-117

9. Diabetes Control and Complications Trial /Epidemiology of Diabetes Interventions and Complications Research Group (2003) Intensive diabetes therapy and carotid intima-media thickness in type 1 diabetes. N Engl J Med 348:2294-2303

10. Diabetes Control and Complications Trial/Epidemiology of Diabetes Interventions and Complications Research Group (2005) Intensive diabetes treatment and cardiovascular disease in patients with type 1 diabetes. N Engl J Med 353:2643-2653

11. Advance Collaborative Group (2005) ADVANCE: Action in Diabetes and Vascular Disease: patient recruitment and characteristics of the study population at baseline. Diabet Med 22:882-888

12. Bastien A (2004) The ACCORD trial: a multidisciplinary approach to control cardiovascular risk in type 2 diabetes mellitus. Pract Diabetol 23:6-11

13. Nathan DM (2002) Initial management of glycemia in type 2 diabetes mellitus. N Engl J Med 347:1342-1349

14. Deeg MA (2005) Basic approach to managing hyperglycemia for the nonendocrinologist. Am J Cardiol 96(Suppl 1):37E-40E

15. Sheehan MT (2003) Current therapeutic options in type 2 diabetes mellitus: a practical approach. Clin Med Res 1:189-200

16. Inzucchi SE (2002) Oral antihyperglycemic therapy for type 2 diabetes. JAMA 287:360-372

17. Klein R, Klein BEK, Moss SE, Davis MD, DeMets DL (1988) Glycosylated hemoglobin predicts the incidence and progression of diabetic retinopathy. JAMA 260:2864-2871

18. Chase HP, Jackson WE, Hoops SL, Cockerham RS, Archer PG, O'Brien D (1989) Glucose control and the renal and retinal complications of insulin-dependent diabetes. JAMA 261:1155-1160

19. American Diabetes Association (2006) Standards of medical care in diabetes-2006. Diabetes Care 29(Suppl 1):S4-42

20. Little RR, Rohlfing CL, Wiedmeyer H-M, Myers GL, Sacks DB, Goldstein DE (2001) The National Glycohemoglobin Standardi- zation Program (NGSP): a five year progress report. Clin Chem 47:1985-1992

21. Expert Panel on Detection, Evaluation, and Treatment of High Blood Cholesterol in Adults (2001) Executive summary of the Third Report of the National Cholesterol Education Program (NCEP) Expert Panel on Detection, Evaluation, and Treatment of High Blood Cholesterol in Adults (Adult Treatment Panel III). JAMA 285:2486-2497

22. Chobanian AV, Bakris GL, Black HR et al (2003) The seventh report of the Joint National Committee on Prevention, Detection, Evaluation and Treatment of High Blood Pressure: the JNC 7 report. JAMA 289:2560-2571

23. DCCT Research Group (1995) The association between glycemic exposure and long-term diabetic complications in the Diabetes Control and Complications Trial. Diabetes 44:968-983

24. Stratton IM, Adler AI, Neil HA et al (2000) Association of glycaemia with macrovascular and microvascular complications of type 2 diabetes (UKPDS 35): prospective observational study. BMJ 321:405-412

25. National Institutes of Health (1999) Clinical guidelines on the identification, evaluation, and treatment of overweight and obesity in adults: the evidence report. Bethesda, Maryland, National Institutes of Health (NIH publication no. 98-4083)

26. Groop L (1992) Sulfonylureas in NIDDM. Diabetes Care 15:737-747

27. Bailey CJ, Turner RC (1996) Metformin. N Engl J Med 334:574-583

28. Malaisse WJ (2003) Pharmacology of the meglitinide analogs: new treatment options for type 2 diabetes mellitus. Treat Endocrinol 2:401-414

29. Van de Laar FA, Lucassen PL, Akkermans RP, Van de Lisdonk EH, Rutten GE, Van Weel C (2005) Alpha-glucosidase inhibitors for type 2 diabetes mellitus. Cochrane Database Syst Rev CD003639

30. Genuth S (1990) Insulin use in NIDDM. Diabetes Care 13:1240-1264

31. Yki-Jarvinen H (2004) Drug therapy: thiazolidinediones. N Engl J Med 351:1106

32. Drucker DJ (2005) Biologic actions and therapeutic potential of the proglucagon-derived peptides. Nat Clin Pract Endocrinol Metab 1:22-31

33. Schmitz O, Brock B, Rungby J (2004) Amylin agonists: a novel approach in the treatment of diabetes. Diabetes 53(Suppl 3): S233-S238

34. Colagiuri S, Cull CA, Holman RR; UKPDS Group (2002) Are lower fasting plasma glucose levels at diagnosis of type 2 diabetes associated with improved outcomes? Diabetes Care 25:1410-1417

35. Harris MI (1991) Epidemiologic correlates of NIDDM in Hispanics, whites and blacks in the U.S. population. Diabetes Care 14(Suppl 3):639-648

36. Rewers M, Hamman RF (1995) Risk factors for non-insulin dependent diabetes. In: Harris M (ed) Diabetes in America. 2nd edition. NIH publication no. 95-1468. National Institutes of Health, Bethesda, Maryland, pp 179-220

37. Pories WJ, Swanson MS, MacDonald KG et al (1995) Who would have thought it? An operation proves to be the most effective therapy for adult-onset diabetes mellitus. Ann Surg 222:339-350

38. Sjostrom L, Lindroos AK, Peltonen M et al (2004) Lifestyle, diabetes, and cardiovascular risk factors 10 years after bariatric surgery. N Engl J Med 351:2683-2693

39. Pontiroli AE, Folli F, Paganelli M et al (2005) Laparoscopic gastric banding prevents type 2 diabetes and arterial hypertension and induces their remission in morbid obesity. Diabetes Care 28:2703-2709

40. Diabetes Prevention Program Research Group (2005) Impact of intensive lifestyle and metformin therapy on cardiovascular disease risk factors in the Diabetes Prevention Program. Diabetes Care 28:888-894 
41. Hadden DR, Montgomery DAD, Skelly RJ et al (1975) Maturity onset diabetes mellitus: response to intensive dietary management. BMJ 3:276-278

42. DeFronzo R, Goodman A, Multicenter Metformin Study Group (1995) Efficacy of metformin in patients with non-insulindependent diabetes mellitus. N Engl J Med 333:541

43. Salpeter S, Greyber E, Pasternak G, Salpeter E (2006) Risk of fatal and nonfatal lactic acidosis with metfromin use in type 2 diabetes mellitus. Cochrane Database Syst Rev CD002967

44. Diabetes Prevention Program Research Group (2002) Reduction in incidence of type 2 diabetes with lifestyle intervention or metformin. N Engl J Med 346:393-403

45. Tessier D, Dawson K, Tetrault JP, Bravo G, Meneilly GS (1994) Glibenclamide versus gliclazide in type 2 diabetes of the elderly. Diabet Med 11:974-980

46. Holstein A, Plaschke A, Egberts E-H (2001) Lower incidence of severe hypoglycemia in patients with type 2 diabetes treated with glimepiride versus glibenclamide. Diabetes Metab Res Rev $17: 467-473$

47. Klimt CR, Knatterud GL, Meinert CL, Prout TE (1970) The University Group Diabetes Program: a study of the effect of hypoglycemic agents on vascular complications in patients with adult-onset diabetes. I. Design, methods and baseline characteristics. II. Mortality results. Diabetes 19(Suppl 2):747-830

48. Rosenstock J, Hassman DR, Madder RD et al (2004) Repaglinide versus nateglinide monotherapy: a randomized, multicenter study. Diabetes Care 27:1265-1270

49. Gerich J, Raskin P, Jean-Louis L, Purkayastha D, Baron A (2005) PRESERVE- $\beta$ : two-year efficacy and safety of initial combination therapy with nateglinide or glyburide plus metformin. Diabetes Care 28:2093-2100

50. Kristensen JS, Frandsen KB, Bayer T, Muller PG (2000) Compared with repaglinide, sulfonylurea treatment in type 2 diabetes is associated with a 2.5 fold increase in symptomatic hypoglycemia with blood glucose levels $<45 \mathrm{mg} / \mathrm{dl}$. Diabetes 49 (Suppl 1):A131 (Abstract)

51. Chiasson JL, Josse RG, Gomis R, Hanefeld M, Karasik A, Laakso M (2003) Acarbose treatment and the risk of cardiovascular disease and hypertension in patients with impaired glucose tolerance: the STOP-NIDDM Trial. JAMA 290:486-494

52. Khan MA, St. Peter JV, Xue JL (2002) A prospective, randomized comparison of the metabolic effects of pioglitazone or rosiglitazone in patients with type 2 diabetes who were previously treated with troglitazone. Diabetes Care 25:708-711

53. Goldberg RB, Kendall DM, Deeg MA et al (2005) A comparison of lipid and glycemic effects of pioglitazone and rosiglitazone in patients with type 2 diabetes and dyslipidemia. Diabetes Care 28:1547-1554

54. Dormandy JA, Charbonnel B, Eckland DJA et al (2005) Secondary prevention of macrovascular events in patients with type 2 diabetes in the PROactive (PROspective pioglitAzone Clinical Trial in macroVascular Events): a randomized controlled trial. Lancet 366:1279-1289

55. Himsworth HP, Kerr RB (1939) Insulin-sensitive and insulininsensitive types of diabetes mellitus. Clin Sci 4:119-152

56. Nathan DM, Roussell A, Godine JE (1988) Glyburide or insulin for metabolic control in non-insulin-dependent diabetes mellitus: a randomized double-blind study. Ann Intern Med 108:334-340

57. Abraira C, Johnson N, Colwell J, VA CSDM Group (1995) Veterans Affairs Cooperative study on glycemic control and complications in type II diabetes. Diabetes Care 18:1113-1123

58. Zammitt NN, Frier BM (2005) Hypoglycemia in type 2 diabetes. Diabetes Care 28:2948-2961
59. Miller CD, Phillips LS, Ziemer DC, Gallina DL, Cook CB, ElKebbi IM (2005) Hypoglycemia in patients with type 2 diabetes mellitus. Arch Intern Med 161:1653-1659

60. Raskin P, Allen E, Hollander P et al (2005) Initiating insulin therapy in type 2 diabetes. Diabetes Care 28:260-265

61. Dailey G, Rosenstock J, Moses RG, Ways K (2004) Insulin glulisine provides improved glycemic control in patients with type 2 diabetes. Diabetes Care 27:2363-2368

62. Hollander PA, Blonde L, Rowe R et al (2004) Efficacy and safety of inhaled insulin (Exubera) compared with subcutaneous insulin therapy in patients with type 2 diabetes. Diabetes Care 27:256-2363

63. Rosenstock J, Zinman B, Murphy LJ et al (2005) Inhaled insulin improves glycemic control when substituted for or added to oral combination therapy in type 2 diabetes. Ann Intern Med 143:549558

64. Cefalu WT, Skyler JS, Kourides IA et al (2001) Inhaled human insulin treatment in patients with type 2 diabetes mellitus. Ann Intern Med 134:203-207

65. Kendall DM, Riddle MC, Rosenstock J et al (2005) Effects of exenatide (exendin-4) on glycemic control and weight over 30 weeks in patients with type 2 diabetes treated with metformin and a sulfonylurea. Diabetes Care 28:1083-1091

66. DeFronzo R, Ratner RE, Han J, Kim DD, Fineman MS, Baron AD (2005) Effects of exenatide on glycemic control and weight over 30 weeks in metformin-treated patients with type 2 diabetes. Diabetes Care 28:1092-1100

67. Buse JB, Henry RR, Han J, Kim DD, Fineman MS, Baron AD; Exenatide-113 Clinical Study Group (2004) Effects of exenatide on glycemic control over 30 weeks in sulfonylurea-treated patients with type 2 diabetes. Diabetes Care 27:2628-2635

68. Heine RJ, Van Gaal LF, Johns D, Mihm MJ, Widel MH, Brodows RG (2005) Exenatide versus insulin glargine in patients with suboptimally controlled type 2 diabetes. Ann Intern Med 143:559-569

69. Hollander PA, Levy P, Fineman MS et al (2003) Pramlintide as an adjunct to insulin therapy improves long-term glycemic and weight control in patients with type 2 diabetes. Diabetes Care 26:784-790

70. Welschen LMC, Bloemendal E, Nijpels G et al (2005) Self-monitoring of blood glucose in patients with type 2 diabetes who are not using insulin: a systematic review. Diabetes Care 28:1510-1517

71. Hirsch IB, Bergenstal RM, Parkin CG, Wright E, Buse JB (2005) A real-world approach to insulin therapy in primary care practice. Clin Diabetes 23:78-86

72. Schwartz S, Sievers R, Strange P, Lyness WH, Hollander P (2003) Insulin $70 / 30$ mix plus metformin versus triple oral therapy in the treatment of type 2 diabetes after failure of two oral drugs. Diabetes Care 26:2238-2243

73. Yki-Jarvinen H, Ryysy L, Nikkila K, Tulokas T, Vanamo R, Heikkila M (1999) Comparison of bedtime insulin regimens in patients with type 2 diabetes mellitus. Ann Intern Med 130:389-396

74. Strowig S, Aviles-Santa ML, Raskin P (2004) Improved glycemic control without weight gain using triple therapy in type 2 diabetes. Diabetes Care 27:1577-1583

75. Fonseca V, Rosenstock J, Patwardhan R, Salzman A (2000) Effect of metformin and rosiglitazone combination therapy in patients with type 2 diabetes mellitus. JAMA 283:1695-1702

76. Bailey CJ, Bagdonas A, Rubes J et al (2005) Rosiglitazone/ metformin fixed dose combination compared with uptitrated metformin alone in type 2 diabetes mellitus: a 24 week, multicenter, randomized, double blind, parallel group study. Clin Ther 27:1548-1561 